\title{
REVisiting MANNER/RESUlt COMPLEMENTARITY: WITH EVIDENCE FROM JAPANESE AND CHINESE VERB COMPOUNDS
}

\author{
Li WENCHAO \\ widelia@zju.edu.cn
}

\begin{abstract}
This paper brings data of verb compounds (V-Vs) from Japanese and Chinese, in an effort to uncover two issues: (a) whether the lexicalisation constraint (i.e. manner/result complementarity) applies to the languages that contain compound verbs; (b) how complex it can be to build compound verb. The finding reveals that manner and result are well encoded in most Japanese verb compounds, which gives rise to the assumption that the complementary constraint is not applicable to Japanese. In Chinese, the application of manner/result complementarity varies according to the types of $\mathrm{V}-\mathrm{V}$. In pair relation $\mathrm{V}-\mathrm{V}$, only manner meaning is conveyed. In predicate-complement $\mathrm{V}-\mathrm{V}$, both manner and result are lexicalised, with V1 encoding the manner and V2 denoting the result. Modifier-predicate V-V appears to only convey the manner. The conclusion emerging from the differing applications in the languages is that the manner/result complementary constraint does not apply to the languages that extensively employ verb compounds.
\end{abstract}

Keywords: lexicalisation; manner/result complementarity; verb compound; Japanese; Chinese

\section{Povzetek}

This paper brings data of verb compounds (V-Vs) from Japanese and Chinese, in an effort to uncover two issues: (a) whether the lexicalisation constraint (i.e. manner/result complementarity) applies to the languages that contain compound verbs; (b) how complex it can be to build compound verb. The finding reveals that manner and result are well encoded in most Japanese verb compounds, which gives rise to the assumption that the complementary constraint is not applicable to Japanese. In Chinese, the application of manner/result complementarity varies according to the types of $\mathrm{V}-\mathrm{V}$. In pair relation $\mathrm{V}-\mathrm{V}$, only manner meaning is conveyed. In predicate-complement $\mathrm{V}-\mathrm{V}$, both manner and result are lexicalised, with V1 encoding the manner and V2 denoting the result. Modifier-predicate V-V appears to only convey the manner. The conclusion emerging from the differing applications in the languages is that the manner/result complementary constraint does not apply to the languages that extensively employ verb compounds.

Ključne besede: leksikalizacija; dopolnjevanje načina in rezultata; glagolske sestavljanke; japonski jezik; kitajski jezik 


\section{Introduction}

Rappaport Hovav and Levin (2010) propose a verb may only lexicalise one type of change, giving rise to manner/result in complementary distribution: a verb may encode manner (1a), or encode result (1b).

(1) a. Verbs encoding a manner

e.g. cry, hit, run, shout, smear, sweep, swim, rub

b. Verbs encoding a result

e.g. arrive, clean, come, open, die, empty, fill

Assuming language can lexicalise only one of the manner or result in the verb, a two category typology is the logical outcome for sentences with one verb explaining the appeal of Talmy's dichotomous typology of lexicalsiation (2000), which relies on whether the core schema of a motion event is conflated with the main verb or the satellite to the main verb. In his view, languages are of two types, i.e. satellite-framed languages (most of the Indo-European languages, the Finno-Ugric families, Chinese, Ojibwa, and Warlpiri) and verb-framed languages (Romance, Semitic, Japanese, Tamil, Polynesian, Bantu, Mayan, Nez Perce, and Caddo languages, Japanese, among others).

Intriguingly, the manner/result complementarity is most manifested in two domains: change of state verbs and motion verbs (Rappaport Hovav \& Levin 2010). In each domain, there are change-of-state verbs, which denote a change of state, as in (2a), or motion in a specified direction, as in (2b).

(2) a. break, crack, fill, empty, melt, open, shatter

b. arrive, come, enter, exit, fall, go, rise

Rappaport Hovav \& Levin (2010)

Crucially, change-of-state verbs (see 2a) denotes events of scalar change, in directed motion verbs (see $2 b$ ), the contiguous points making up the path of motion constitute a scale. Given this, manner/result complementarity can be tackled as the lexicalisation of a scalar change being in complementary distribution with the lexicalisation of a nonscalar change.

The theory of manner/result complementarity appears quite pervasiveness and has been welcomed among linguists, who study Indo-European languages. On the other hand, many scholars from different camps have voiced their concerns with this hypothesis (Cifuentes Ferez 2007:122; Goldberg 2010:48-49; Beavers and KoontzGarboden 2012, Kubota 2011). They argue that manner/result complementarity perhaps is not the consequence of a lexicalisation constraint, but merely a tendency regarding verb meanings. An immediate counterexample that springs to mind is the English motion verb swim, which appears to lexicalise both manner and change of location. Moreover, verb break also serves as a putative counterexample, c.f. (3).

(3) a. Terry broke the record.

b. *The record broke. 
The ungrammaticality of (3) indicates that in the context of 'record break', an explicit manner component of agency is involved.

The limitations in RH\&L's hypothesis further extend to East Asian Languages, whereby verb compounds (V-Vs) are extensively employed. V-V compounds can be composed by scalar change with a non-scalar change and crucially, manner/result seem to manifest itself in compounds, as in (4).

(4) Shuzhi chui-duan /zhe-duan le.

Branch blow-break/snap-break PERF

'The branch was blown/snapped.'

In Chinese, most words are morphologically simple as there is no developed notion of a stem. As a result, manner/result manifests itself in compounds. Here V-V zheduan 'snap-break' entails both manner and result. V1 bears semantic elements expressing manner and indicates a concrete action. But such action verb does not imply an accomplishment or an achievement; hence, an addition of complement representing the perfect is employed, as V2. Hence, V1 and V2 are not in complementary distribution; rather, they are assigned to an equal status. Furthermore, a variety of V2 are allowed, and generally, $\mathrm{V} 2 \mathrm{~s}$ are born by a resultative complement such as hao'good', man 'full', guang, 'over'. Further examples are like kao-hao 'bake-over'.

Given this, it seems necessary to revisit the issue by bringing the verb compounding data from Japanese and Chinese.

The purpose of this paper is two-fold. First, it explores how complex it can be to build a motion V-V or a change-of-state V-V in Japanese and Chinese. Second, it exams whether the manner/result in complementary constraint applies to the languages in focus.

This paper is mapped out as follows: Section 2 provides an insight into the framework: scale-base approach. Section 3 explores the lexicalsiation constraint in Japanese and enumerates the possibilities of verb compounding. Section 4 is devoted to lexicalsiation constraint in Chinese. Section 5 discusses the results and provides a conclusion to this paper.

\section{Scale-based approach to manner/result complementarity}

This paper follows the scalar structure in an effort to explore lexicalisation constraint on verb compounding in Japanese and Chinese. The data for Chinese is adopted from the corpus of Modern Chinese constructed by the Center for Chinese Linguistics at Beijing University. The data for Japanese is from the corpus of Balanced Corpus of Modern Written Japanese by National Institute for Japanese language and linguistics. This paper also uses hand-made examples. And native speakers check all the hand-made examples. 
According to Kennedy (2001) and Kennedy and McNally (2005), a scale is constituted by a set of degrees (points or intervals indicating measurement values) on a particular dimension (e.g. cost, depth, height, temperature), with an ordering relation. The dimension represents an attribute of an entity, with the degrees indicating the possible values of this attribute. Incorporating this, Levin (2010) notes that a scalar change in an entity involves a change in the value of one of its scalar-valued attributes in a particular direction on the relevant scale. Consequently, verbs that lexically specify a scale are called scalar change verbs, as in (5a). Verbs that do not lexicalise a scale are referred to as nonscalar change verbs, as in $(5 \mathrm{~b})$ :

(5) a. scalar change verbs: warm, cool, freeze, fall, rise...

b. nonscalar change verbs: roll, exercise, scream, laugh, jog...

There are two types of attributes, which give rise to two types of scalar change verbs:

(6) a. change-of-sate verbs (COS): warm, cool, freeze, stretch...

b. Inherently directed motion verbs (IDM): arrive, fall, rise, approach...

In the COS domain, the relation to the standard correlates with the direction of change, i.e. with an increase or decrease in value of the attribute, such as 'We froze the ice cream solid' (Rappaport Hovav \& Levin 2010: 29). In the domain of motion, as Rappaport Hovav and Levin (2010) note, a scale can be understood in regard to the dimension of distance, i.e. the distance of the moving object with respect to the reference object (Rappaport Hovav \& Levin 2010: 29). For example, the points in the scale of arrive are ordered in a direction stretching from the reference object, i.e. the starting point of the departure and the event we are heading towards.

\section{Lexicalisation constraint in Japanese}

In Japanese, there are about five ways of building a lexical compound verb (c.f. Yumoto 1996, 2005, 2008). Essentially, manner uses as well as the result components co-exist, as illustrated in (7).
a. Pair relation

kake-meguru 'run about'; hashiri-mawaru 'run about'

b. Means

tuki-otosu 'push-cause.fall'; naki-otosu 'cry-cause.fall'

c. Cause-effect

naki-harasu 'cry-cause.swell'; obore-shinu 'drown die'; yake-shinu 'burnt die'

d. Accompanying state/manner

hai-yoru 'crawl towards'; koroge-otiru 'tumble-fall'

e. Complement relation

mi-nogasu 'overlook'; kaki-otosu 'forget to write' 
The pair relation $\mathrm{V}-\mathrm{V}$ is generally composed of [transitive $\mathrm{V}+$ unergative $\mathrm{V}$ ]. This type of $\mathrm{V}-\mathrm{V}$ comes to justify the manner/result complementary constraint. There are two ways of building the $\mathrm{V}-\mathrm{V}$, (a) $\mathrm{V}-\mathrm{V}$ is composed by two components that denote a manner. kakemeguru 'run about' is an illustration of this type. The two morphemes kakeru 'run' and V2 meguru 'run' are non-scalar change morphemes and both are not bound, apparently receiving an equal semantic status. (b) V-V is composed by two components that denote a result, e.g. warikiru 'break-cut', warisaku 'break-split'. Crucially, in the two formations, V1 and V2 both function as the head (cf. Kageyama 1993, Fukushima 2005).

Means $\mathrm{V}-\mathrm{V}$ is very productive and it contains three argument structure variations, as shown in Table 1. It appears that the compound is headed by V2. The first constituents express the means of the change of location or change of state carried out by $\mathrm{V} 2 \mathrm{~s}$.

Table 1. Variation of argument structure and composition in Means V-V

\begin{tabular}{|c|c|c|}
\hline Argument structure $^{1}$ & Composition & Example \\
\hline 1. $\operatorname{tran} . \mathrm{V}+$ unacc. $\mathrm{V}$ & change of state + change of location & wake-iru, kiri-iru \\
\hline 2. $\operatorname{tran} . \mathrm{V}+$ unacc. $\mathrm{V}$ & action + change of location & fuki-agaru, uchi-agaru \\
\hline 3. $\operatorname{tran} . V+\operatorname{tran} . V$ & action + change of location & $\begin{array}{l}\text { oshi-susumeru, } \\
\text { oshi-modosu }\end{array}$ \\
\hline 4. $\operatorname{tran} . V+\operatorname{tran} . V$ & action + change of state & $\begin{array}{l}\text { naguri-korosu, } \\
\text { oshi-tsubusu }\end{array}$ \\
\hline
\end{tabular}

Cause-effect V-V is considered the least productive type among lexical V-Vs. It contains the following different argument structure and composition methods:

Table 2. Different argument structures and compositions in Cause-effect V-V

\begin{tabular}{|c|c|c|}
\hline Argument structure & Composition & Example \\
\hline 1. unerg. $\mathrm{V}+$ unacc. $\mathrm{V}$ & action + change of state & $\begin{array}{l}\text { naki-tsukareru, } \\
\text { aruki-tsukareru }\end{array}$ \\
\hline 2. unacc. $\mathrm{V}+$ unacc. $\mathrm{V}$ & change of location + change of location & $\begin{array}{c}\text { koroge-ochiru, } \\
\text { suberi-ochiru }\end{array}$ \\
\hline 3. unacc. $\mathrm{V}+$ unacc. $\mathrm{V}$ & change of state + change of state & $\begin{array}{l}\text { yase-kokeru, } \\
\text { oshi-yoseru }\end{array}$ \\
\hline 4. unacc. $\mathrm{V}+$ unacc. $\mathrm{V}$ & change of state + change of location & $\begin{array}{l}\text { koori-tsuku, } \\
\text { yake-ochiru }\end{array}$ \\
\hline
\end{tabular}

\footnotetext{
${ }^{1}$ tran: transitive, unacc: unaccusative, unerg: unergative
} 
As seen from Table 2, V1 denotes the cause or designates the path of motion/COS and can be conveyed by either an agentive or a non-agentive verb, e.g. aruku 'walk', korogeru 'tumble'. V2s contribute to the change of location or change of state and usually entail a destination of a motion or an endpoint of a motion or COS event, e.g. ochiru 'fall', tsuku 'stick to', which, in light of scalar structure, would be regarded as closed-scale morphemes.

The accompanying state/manner V-V contains the following argument structure:

Table 3. Variation of argument structure and composition in Manner V-V

\begin{tabular}{lcc}
\hline Argument structure & Composition & Example \\
\hline uner.V + uner.V & agentive motion + change of location & tobi-agaru, tachi-agaru \\
\hline
\end{tabular}

V1s entail a figurative sense, describing how quick the action agaru 'ascend' or noboru 'climb' is. In this sense, V1s behave like modifiers and the motion paths are lexicalised into the second constituents, which should be considered the head.

Complement relation V-Vs, as Yumoto (1996) and Matsumoto (1996) argue, are composed by a cause component with a result component. The second constituent, which indicates the change of state, is usually denoted by a transitive verb or an accusative verb. Moreover, V2s seem to have received affixation. Thus, the whole compound is related to a metaphorical reading, e.g. mi-nogasu 'overlook', hohoemikaesu 'smile back', seme-kakeru 'attack'. In addition, apart from the accusative case, complement relation V-Vs are also likely to take a dative case, as can be seen from kare ni hohoemi-kaesu 'smile back at him' and teki ni seme-kakeru 'attack the enemy'.

With this in place, we can pause and draw a preliminary conclusion: the manner/result in complementary constraint does not seem to apply to Japanese. In most verb compounds, both manner and result are pretty well encoded. Verb compounds along with the lexicalisation constraint are given in Table 4.

Table 4. Verb compounds along with the lexicalisation constraint

\section{Verb compounds Encoding component Lexicalisation Constraint}

\section{Means V-V}

(a). $\operatorname{tran} . \mathrm{V}+$ unacc. $V$

(b). $\operatorname{tran} . \mathrm{V}+$ unacc. $\mathrm{V}$

(c). $\operatorname{tran} . \mathrm{V}+\operatorname{tran} . \mathrm{V}$

(d). $\operatorname{tran} . \mathrm{V}+\operatorname{tran} . \mathrm{V}$ both manner and result

both manner and result

both manner and result

both manner and result not applied

not applied

not applied

not applied 


\section{Cause-effect V-V}
(a). unerg. $V+$ unacc. $V$
(b). unacc. $\mathrm{V}+$ unacc. $\mathrm{V}$
(c). unacc. $\mathrm{V}+$ unacc. $\mathrm{V}$
(d). unacc. $\mathrm{V}+$ unacc. $\mathrm{V}$

both manner and result

not applied

both manner and result

not applied

both manner and result

not applied

both manner and result

not applied

\section{Manner V-V}

uner. $\mathrm{V}$ + uner. $\mathrm{V}$

manner

applied

\section{Lexicalisation constraint in Chinese}

As touched upon in Section 1, manner/result appear to manifest itself in compounds in Chinese. In order to answer the question of whether the manner/result complementary constraint applies to Chinese, this section first looks into the types of verb compounds and then moves on to the distribution of the two components of V-Vs.

\subsection{Types of verb compounds in Chinese}

According to Kageyama (1996), verbs are divided into two types: transitive and intransitive. Intransitive verbs can be further classified into unergative verbs, which represent an act or action, and ergative verbs or unaccusative verbs, which represent [change + resultative state]. From a semantic viewpoint, an ergative verb is a kind of verb that represents the change of an object in terms of its own property. With the change of the causer, it can also be used as a transitive verb. On the other hand, an unaccusative verb is not affected by external force, but instead represents events or states that occur naturally and, hence, it is acceptable as a transitive verb. The argument structures of these verbs are described in (8):
a. Transitive verb: $(x, y)$
b. unergative verb: $(x \quad)$
c. ergative verb: $(y)$
d. unaccusative verb: $(y)$

(external argument, internal argument)

(external argument)

(internal argument)

(internal argument)

Kageyama (1996)

In light of this argument structure, this paper suggests that Chinese verb compounds fall into two groups, i.e. lexical V-V and syntactic V-V. The lexical class includes pair relations and predicate-object types. The syntactic class has the following subtypes: predicate-complement V-V, modifier-predicate V-V and subject-predicate V$\mathrm{V}$. The classifications are illustrated in (9) and (10): 
(9) Lexically-formed group

a. Pair relation $\mathrm{V}-\mathrm{V}$

[unergative + unergative]

bēn-păo 'run-run'

b. Predicate-Object V-V

[transitive $+\mathrm{N}$ ]

chōng-diàn 'charge'

(10) Syntacticly-derived group

a. Predicate-Complement V-V

( i) [transitive + unergative] (subject-oriented)

kàn-lèi 'watch-tired'

(ii) [unergative + unaccusative] (object-oriented)

$k \bar{u}-s h \bar{\imath}$ 'cry-wet'

(iii) [transitive + unacsusative] (object-oriented)

tuī-kaī 'push-open'

(iv) [unergative + unaccusative] (subject-oriented)

$k \bar{u}$-lèi 'cry-tired'

b. Modifier-Predicate V-V

hé-chàng 'together-sing'

c. Subject-Predicate V-V

tóu-téng 'head-pain'

The lexical V-Vs class seems to add a syllabic filter to the derivation, as most of them entail bisyllables. Moreover, lexical V-Vs appear to be highly lexicalised and hence probably requires a certain idiomatic reading. On the other hand, it occurs that the syntactic V-V class has fewer phonological restrictions.

\subsection{Lexicalisation in Chinese verb compounds}

In light of the classification of verb compounds, we are now in a position to find out whether manner/result compementarity applies to Chinese. (9a), i.e. Pair relation V-V, and (10a), i.e. Predicate-Complement V-V and (10b), i.e. Modifier-Predicate V-V will be the primary focus; (9b), i.e. Predicate-Object V-V and (10c), i.e. SubjectPredicate V-V will not be tackled.

Our starting point is the lexical compound, which is represented by pair relation and is illustrated in bèn-păo 'run-run', as in (11): 
(11) Zhāng sān zài bēn păo.

Zhāng sān PROG run-run

'Zhāng sān is running.'

The pair relation type of compound is composed by two non-scalar change motion morphemes, i.e. V1 bēn 'run' and V2 păo 'run'. The two morphemes have the same meaning and scalar properties. They are considered to be a synonymous lexicon. The events represented by V1 and V2 are classified as the same categories (i.e. both of them are motion events). Moreover, phonologically, such compounds usually appear to be bisyllabic words. Therefore, syntactically, semantically and phonologically, the two motion morphemes are equipollent. Given this, we consider the 'Non-scalar change motion morphemes' pattern of motion events perform equipollent framing. Other examples displaying this strategy include fêi-xiáng 'fly-fly'.

Moving on to syntactic compounds. We begin with the predicate-complement V$\mathrm{V}$. This type of $\mathrm{V}-\mathrm{V}$ is composed of a resultative complement to a verb V1. Two ways of building are found: ( $\mathrm{i}$ ) [unergative $\mathrm{V}+$ adjective] (12a); and ( ii ) [transitive V + unaccusative V] (12b):

(12) a. [unergative $\mathrm{V}+$ Adjective]

$k \bar{u}$-shì 'cry-wet'

b. [transitive $\mathrm{V}+\mathrm{Adj}]$

dă-pò 'hit-broken'

The action verb, i.e. V1 does not imply an accomplishment or an achievement. The second constituents play the role of resultative complements, expressing a state or the result of an action. To note, the category of the complements is debatable; Li and Thompson et al. (1981) regard them as adjectives but, for Palmer (2005), they are argued to be stative verbs. Despite such debate, there is no doubt that this verbal weakening is a typical manifestation of grammaticalisation and, hence, these complements should be considered to be satellites rather than substantive verbs.

This is backed up by the 'scalar structure' perspective. V2s can be open-scale adjective predicates (APs) (e.g. hăo 'good') or closed-scale APs (măn 'full'; guāng, 'over'). A variety of such V2s are allowed by V1 and crucially these Vs are not able to occur by themselves. In this regard, we can assume that it is the first constituent that determines the transitivity of the whole and thus it should be viewed as the head. The resultative (V2) should be considered as being framed outside the verb roots.

Now, we come to modifier-head type. This type of $\mathrm{V}-\mathrm{V}$ is headed by $\mathrm{V} 2$. The former event represented by V1 plays roles of explanation, description and restriction on the latter event represented by V2, as illustrated in (13):

(13) Zhāngsān bèi Lǐsì zhuī shā.

Zhāngsān PASS Lǐsì chase-kill 
' Zhāngsān is chased by Lǐsì and Lǐsì intends to kill him.'

The compound exhibits two events, i.e. a motion event denoted by the former constituent and a change-of-state event rendered by the latter constituent. The two morphemes are not bound and both are atelic. Essentially, this type of V-Vs only lexicalise manner. As seen in (13), the result meaning drops out, as V1 zhuī, 'chase' is a modifier, describing the manner of the action, carried by V2 shā, 'kill'. Other examples include hé-chàng 'together-sing', etc.

To sum up briefly, the Chinese verb compounds obviously can serve as counterexamples to the 'manner/result complementary constraint'. However, the application of the constraint varies according to the types of V-Vs. In pair relation $\mathrm{V}$ $\mathrm{V}$, the two constituents are assigned to an equal syntactic, morphological and semantic status; essentially only manner meaning is conveyed. In this sense, the lexicalisation constraint appears to apply to pair relation $\mathrm{V}-\mathrm{V}$. In predicate-complement $\mathrm{V}-\mathrm{V}$, both manner and result are lexicalised, i.e. V1 encodes the manner and V2 denotes the result. As a result, the lexicalisation constraint fails to apply. Finally modifier-predicate $\mathrm{V}-\mathrm{V}$ seems to only encode the manner meaning, which comes to justify the lexicalisation constraint. Verb compounds along with the lexicalisation constraint are given in Table 5.

Table 5. Verb compounds along with the lexicalisation constraint

Verb compounds

1. Pair relation V-V

2. Predicate-Complement V-V

( i) [transitive + unergative] both manner and result

(ii) [unergative + unaccusative] both manner and result

(iii) [transitive + unacsusative] both manner and result

(iv) [unergative + unaccusative] both manner and result

3. Modifier-Predicate V-V manner

\section{Encoding component}

Lexicalisation Constraint

manner applied

not applied

not applied

not applied

not applied

applied

\section{Conclusion}

This paper brings data of verb compounds (V-Vs) from Japanese and Chinese, in an effort to uncover two issues: (a) whether the manner/result in complementary constraint applies to the languages that contain compound verbs; (b) how complex it can be to build compound verb. The finding reveals that manner and result are well encoded in most Japanese verb compounds, which gives rise to the assumption that the complementary constraint is not applicable to Japanese. In Chinese, the application of 
manner/result complementarity varies according to the types of $\mathrm{V}-\mathrm{V}$. In pair relation $\mathrm{V}-\mathrm{V}$, only manner meaning is conveyed. In predicate-complement $\mathrm{V}-\mathrm{V}$, both manner and result are lexicalised, with V1 encoding the manner and V2 denoting the result. Modifier-predicate V-V appears to only convey the manner. The conclusion emerging from the differing applications in the languages is that the manner/result complementary constraint does not apply to the languages that extensively employ verb compounds.

\section{References}

Beavers, John and Andrew Koontz-Garboden. 2012. Manner and result in the roots of verbal meaning. Linguistic Inquiry 43:331-369.

Cifuentes Ferez, Paula. 2007. Human Locomotion Verbs in English and Spanish, International Journal of English Studies 7, 117-136.

Goldberg, Adele E. 2010. Verbs, Constructions and Semantic Frames, in E. Doron, M.

Rappaport Hovav, and I. Sichel, eds., Syntax, Lexical Semantics, and Event Structure, Oxford University Press, Oxford, UK, 21-38.

Fukushima, Kazuhiko. 2005. Lexical V-V compounds in Japanese: Lexicon vs. Syntax. Language 81, 568-612.

Kageyama, Taro. 1993. Bunpou to gokeisei. Hitsuji Syobo Publishing.

Kageyama, Taro. 1996. Doushiimiron-gengo to ninchi no setten. Kuroshio.

Kageyama, Taro. 1999. Word formation. In The Handbook of Japanese Linguistics, ed. Natsuko Tsujumura. Malden, MA: Blackwell Publishers.

Kennedy, Christopher and Beth Levin. 2008. Measure of change: The adjectival core of degree achievements. In C. Kennedy and L. McNally, eds., Adjectives and Adverbs: Syntax, Semantics and Discourse, 156-183. Oxford: Oxford University Press.

Kennedy, C. and L. McNally. 2005. Scale structure and the semantic typology of gradable predicates. Language, 81(2): 345-381.

Kubota, Yusuke. 2011. Revisiting the progressive/perfect ambiguity of -te iru in Japanese: A scale-based perspective. Paper to be presented at CSSP 2011.

Li, Charles. N. \& Thompson, Sandra. A. 1981. Mandarin Chinese: A functional reference grammar. University of California Press.

Palmer, Martha, Dan, Gildea and Paul Kingsbury. 2005. The proposition bank: An annotated corpus of semantic roles. Computational Linguistics 31(1), 2005.

Rappaport Hovav, Malka and Beth Levin. 2010. Reflections on manner/result complementarity. In M. R. Hovav, E. Doron, and I. Sichel, eds., Lexical Semantics, Syntax, and Event Structure, 21-38. Oxford: Oxford University Press.

Talmy, Leonard. 2000a. Toward a cognitive semantics, vol.1: concept-structuring systems. Cambridge, Mass.: MIT Press.

Talmy, Leonard. 2000b. Toward a cognitive semantics, vol.2: typology and process in concept structuring. Cambridge, Mass.: MIT Press.

Yumoto, Yoko. 1996. Gokoosei to goi gainen kouzoo-Nihongo no 'doushi + doushi' no fukugougo keisei ni tsuite. Gengo to Bunka no Shosou-Okuda Hiroyuki Kyouju Taikan Kinen Ronbunshuu. 
Yumoto, Yoko. 2001. Dooshi kara doo o keisei suru gokeisei ni okeru kaihannchuuka sosei no uketugi nit suite. Gengo kenkyū 119, 453-473.

Yumoto, Yoko. 2005. Fukugoo dooshi \& hasei doushi no imi to tougo-Mojuuru keitairon kara mita nichi-eigo no doushi keisei. Hituzi Syobo Publishing.

Yumoto, Yoko. 2008. Fukugoo dooshi ni okeru koo jitugen - Toogo teki fukugoo to goiteki fukugoo no sai -. Morphology and Lexicon Forum 4. 